\title{
Quantification of Phenolic Compounds by HPLC-DAD and In vitro Antioxidant Activity of Root Extract of Echinops kebericho Mesfin (Asteraceae)
}

\author{
Engeda Dessalegn $^{1^{*}} \quad$ H. P. Vasantha Rupasinghe ${ }^{2}$ \\ 1.Chemistry Department, Hawassa College of Education, P.O. Box 115, Hawassa, Ethiopia, \\ 2.Department of Environmental Sciences, Faculty of Agriculture, Dalhousie University P.O. Box 550, Truro, \\ Canada, B2N 5E3
}

\begin{abstract}
Echinops kebericho Mesfin is wild endemic medicinal herb to Ethiopia and the root is used traditionally for the treatment infectious and non-infectious diseases. This study was designed to identify and quantify the phenolic compounds and in vitro antioxidant activity of the root extracts. Seven phenolic acids, six flavanols, and two aliphatic organic acids were analyzed by high performance liquid chromatography-diode array detector (HPLCDAD), among which hydroxycinnamic acid $(413.14 \pm 6.60 \mu \mathrm{g} / \mathrm{g})$, quercetin-3-O-galactoside $(7.07 \pm 0.34 \mu \mathrm{g} / \mathrm{g})$ and succinnic acid $(702.95 \pm 42.54 \mu \mathrm{g} / \mathrm{g})$ were the major components. The methanol extract exhibited the highest total phenolics (29.14 \pm 0.38 milligram gallic acid equivalent gram of dried extract), total flavonoid content (1.08 \pm 0.03 milligram of quercitin equivalent/gram of dried extract), and antioxidant activities followed by ethanol and water extracts. Antioxidant capacity were $99.96 \pm 7.53 \mu \mathrm{g} / \mathrm{mL}$ and $246.88 \pm 15.60 \mu \mathrm{g} / \mathrm{mL}$ as determined by the $\mathrm{DPPH}\left(\mathrm{IC}_{50}\right)$, ferric reducing power ( $\left.\mathrm{IC}_{50}\right)$ assays, respectively. Total phenolic content (TPC) and total flavonoid content (TFC) were strongly correlated with DPPH $\left(\mathrm{R}^{2}=0.93, \mathrm{R}^{2}=0.91\right)$ and ferric reducing power $\left(\mathrm{R}^{2}=0.98\right.$, $\left.\mathrm{R}^{2}=0.71\right)$, respectively. The study revealed that crude root extract of E. kebericho can be used as natural antioxidants as well as for preventing oxidative stress mediated human disorders.
\end{abstract}

Keywords: Antioxidant activity; DPPH; ferric reducing; Herb; Echinops kebericho; phenols

DOI: $10.7176 / \mathrm{CPER} / 62-02$

Publication date: January $31^{\text {st }} 2020$

\section{Introduction}

Echinops kebericho Mesfin (Asteraceae), locally called 'kebericho', an endangered endemic erect massive root stock- bearing perennial shrub, known only in Ethiopia, is among the most important medicinal plants of the country (Muluken and Tileye, 2019). Reports and ethnobotanical surveys showed long traditional use of the plant for preparation of medicines against migraine, mental illness, heart pain, lung TB, leprosy, diarrhea, kidney disease, malaria, billharzia, and, amoebic dysentery (Abebe and Ahadu, 1993; Fisseha and Workineh, 2013; Gadisa. 2019; Helen and Araya, 2019). The root is burned for smoke to ward off mosquitoes and as a snake repellant, inhaled to fight typhus and fever, and also known to be used as a fumigant, mainly after childbirth in rural areas (Teklehaymnit et al., 2007). The steam distilled essential oil displayed a strong activity against Leishmania aethiopica and Leishmania donovani (Tariku et al., 2011). Extracts and essential oils of the roots of E. kebericho were assessed for their antimicrobial (Ashebir and Ashenafi, 1999; Belay et al., 2011; Gemechu et al., 2015), antihelminthic, taenicidal, and molluscicidal activities (Ariaya and kidane, 1991; Ariaya et al., 2005; Jemal et al., 2011). According to the study conducted by Alemayehu et al. (2015), 70\% ethanol root extract showed antiplasmodial and toxicological effect in treatment of malaria in Ethiopia. In another study, 70\% methanol extract of E. kebericho showed Antiplasmodial activities against Plasmodium Berghei in a dose dependent Manner (Abdissa et al., 2018). Similarly, in vitro and in vivo techniques on hydromethanolic root extract showed antitrypanosomal effect against Trypanosoma congolense field isolate (Debela et al., 2019). Also hydromethanolic and ethanol root extracts showed in vivo Anti-schistosomal activities (Yonas et al., 2018)

The main volatile constituent found in root hydrodistilled essential oil was eudesm-7(11)-en-4-ol, followed by caryophyllene oxide and $\tau$-cadinol (sesquiterpenes) and few monoterpenoids (Ariaya et al., 2007). Chemical studies on the smoke of roots (Tadesse Abegaz et al., 1990) revealed the presence of two highly bioactive sesquiterpene compounds known as dehydrocostus lactone and costunolide. To our knowledge no study has been reported on phenolic content and antioxidant activity of E. kebericho. Therefore, this study was conducted to characterize and quantify the phenolic contents and antioxidant activity of root extracts of E. kebericho Mesfin for the first time.

\section{Materials and Methods}

\subsection{Standards and reagents}

Caffeic acid (Caf), ferulic acid (Fer), isoferulic acid (Isofer), and purchased from Chroma Dex (Santa Ana, CA, USA). Quercetin-3-O-galactoside (Q3-gal) and quercetin-3-O-rhamnoside (Q3-rha) were purchased from Indofine 
Chemical Co. (Hillsborough, NJ, USA). Quercetin-3-O-glucoside (Q3-glu), quercetin-3-O-arabinoglucoside (Q3arglu), chlorogenic acid (Chl), 4-Hydroxybenzoic acid (4-Hydrob), hydroxycinnamic acid (Cinam), fumaric acid (Fum), succinic acid (Suc), syringic acid (Syr), quercetin (Qu), quercetin-3-O-rutinoside (Q3-rut), DPPH, sodium carbonate, and Folin-Ciocalteu reagent, gallic acid, and butylated hydroxytoluene (BHT) were purchased from Sigma-Aldrich (St. Louis, MO, USA). The other chemicals and solvents used in this experiment were of analytical grade reagent.

\subsection{Plant Materials}

\subsection{Collection and Preparation of plant extracts}

Roots of E. kebericho were collected from Wondo Genet Agricultural research center, South Ethiopia, in June, 2014. Fresh roots were air dried for twenty days and then ground to fine powder using electric grinder (FM100 model, China). The chloroform, water, and, methanol extracts of all were prepared by dissolving $10 \mathrm{~g}$ of the fine powder separately in $100 \mathrm{~mL}$ each solvent. The contents were kept in orbital shaker for $6 \mathrm{~h}$ at room temperature. Thereafter, each extract was filtered using Whatman no.1 filter paper and evaporated to dryness under vacuum at $40^{\circ} \mathrm{C}$ by using a rotary evaporator (Buchi, 3000 series, Switzerland). For the chromatography (LC-MS) analysis, the methanol extract was further filtered through $0.2 \mathrm{~cm}$ syringe. The extraction was done in triplicate for each solvent and the resulting extracts were stored in a sealed plastic container at $4^{\circ} \mathrm{C}$ until further investigation.

\subsection{Determination of phenolic contents}

The TPC was estimated by Folin-Ciocalteu method as described in Shan et al. (2005) with slight modification. To $0.3 \mathrm{~mL}$ of the extract $(1 \mathrm{mg} / \mathrm{mL}), 1.5 \mathrm{~mL}$ Folin-Ciocalteu reagent (diluted ten times) was added and the mixture was left for $5 \mathrm{~min}$ and then $1.5 \mathrm{~mL}(7.5 \% \mathrm{~g} / \mathrm{v})$ of sodium carbonate was added. The absorbance of the resulting blue color was measured at $765 \mathrm{~nm}$ with a UV- visible spectrophotometer (JENWAY, 96500, UK) after incubation for $90 \mathrm{~min}$ at room temperature. The TPC in the extract was estimated from gallic acid $(1-100 \mu \mathrm{g} / \mathrm{mL})$ calibration curve $\left(y=0.023 x+0.048, R^{2}=0.997\right)$ and results were expressed as milligram gallic acid equivalent/gram of dry extract (mg GAE/g).

\subsection{Total flavonoid content}

The TFC was determined as described in Ayoola et al. (2008) with minor modifications. The analysis was based on the formation of yellow color of flavonoid-aluminium complex. Aluminum chloride $(2 \mathrm{~mL}, 2 \%)$ was mixed with the same volume of the leaf extract $(1 \mathrm{mg} / \mathrm{mL})$. Individual blanks were prepared consisting of $2 \mathrm{~mL}$ of sample solution and $2 \mathrm{~mL}$ of methanol without aluminum chloride. Then absorbance readings at $415 \mathrm{~nm}$ were taken after $1 \mathrm{~h}$ of incubation at room temperature against a blank sample. The TFC was determined using a standard curve of quercetin at $(1-40 \mu \mathrm{g} / \mathrm{mL})$ and values were calculated as milligram quercetin equivalents/gram of dried extract $(\mathrm{mgQRE} / \mathrm{g})$ using the following equation based on the quercetin calibration curve: $\mathrm{y}=0.024 \mathrm{x}+0.112, \mathrm{R}^{2}=0.991$.

\subsection{Identification of phenolic compounds}

Separation and identification of phenolic compounds were carried out by using HPLC coupled to electrospray ionization and triple quadrupole mass spectrometry (LC-MS) as described by Rupasinghe et al. (2010). The analyses of phenolic compounds in the extracts were performed using a Waters Alliance 2695 separations module (Waters, Milford, MA, USA) coupled with a Micromass Quattro micro API MS/MS system and controlled with Mass Lynx V4.0 data analysis system (Micromass, Cary, NC, USA). Electrospray ionization in negative ion mode was used in the multiple reaction mode of mass spectrometric analysis. The column used was an Allure biphenyl $(100 \mathrm{~mm} \times 2.1 \mathrm{~mm})$ (Restek Chromatography Products, Bellefonte, PA, USA). For the separation of the flavonol, phenolic acid, and aliphatic organic acids, the mobile phase consisted of $0.1 \%$ formic acid in water (solvent A) and $0.1 \%$ formic acid in acetonitrile (solvent B) at a flow rate of $0.35 \mathrm{~mL} / \mathrm{min}$. A linear gradient profile was used with the following proportions of solvent A applied at time $\mathrm{t}(\mathrm{min}) ;(\mathrm{t}, \mathrm{A} \%):(0,94 \%),(2,83.5 \%), 2.61,83 \%)$, $(2.17,82.5 \%), 3.63,82.5 \%),(4.08,81.5 \%), 4.76,80 \%), 6.75,20 \%),(8.75,94 \%),(12,94 \%)$. The retention time of each compound was compared with the retention time of the standards in different mobile phases. The peaks, showing the same retention time as that of the standards, were preliminary identified and were further analyzed by MS. The MS was used to get the molecular weights of the compounds by scanning from 50 to $1500 \mathrm{~m} / \mathrm{z}$.

\subsection{Quantification of phenolic compounds}

For the quantitative analysis of phenolic compounds, a calibration curve was obtained by injection of known concentrations $(2.5-100 \mu \mathrm{g} / \mathrm{mL})$ of different standards compounds: caffeic acid $\left(\mathrm{y}=12161.281 \mathrm{x}+15193.95 ; \mathrm{R}^{2}=\right.$ 0.999); chlorogenic acid $\left(y=2426.04 x+2982.54 ; \mathrm{R}^{2}=0.998\right)$; ferulic acid $\left(\mathrm{y}=2590.53 \mathrm{x}+4051.16 ; \mathrm{R}^{2}=0.995\right)$; isoferulic acid $\left(\mathrm{y}=461.42 \mathrm{x}+39.11 ; \mathrm{R}^{2}=0.999\right)$; quercitin-3-O-glucoside $\left(\mathrm{y}=9649.17 \mathrm{x}+4449.30 ; \mathrm{R}^{2}=0.999\right)$; quercitin-3- $O$-galactoside $\left(\mathrm{y}=2853.93 \mathrm{x}+8285.48 ; \mathrm{R}^{2}=0.999\right)$; quercitin-3-O-rutinoside $(\mathrm{y}=7947.03 \mathrm{x}+2168.42 ;$ $\left.\mathrm{R}^{2}=0.999\right)$; quercetin $\left(\mathrm{y}=19925.94 \mathrm{x}+33058.53 ; \mathrm{R}^{2}=0.986\right)$; quercetin-3-O-rhaminoside $(\mathrm{y}=10784.83 \mathrm{x}+$ 
8917.24; $\left.\mathrm{R}^{2}=995\right)$; quercetin-3-O-arabinoglucoside $\left(\mathrm{y}=6688.89 \mathrm{x}+1751.29 ; \mathrm{R}^{2}=0.999\right)$; fumaric acid $(\mathrm{y}=$ $\left.180.777 \mathrm{x} ; \mathrm{R}^{2}=0.978\right)$ 4-Hydroxybenzoic acid $\left(\mathrm{y}=847.02 \mathrm{x}+161.43 ; \mathrm{R}^{2}=989\right)$; hydroxycinnamic acid $(\mathrm{y}=$ $\left.1534.72 \mathrm{x}+330.12 ; \mathrm{R}^{2}=956\right)$; succinic acid $\left(\mathrm{y}=1266.91 \mathrm{x}+151.77 ; \mathrm{R}^{2}=0.950\right)$; syringic acid $(\mathrm{y}=1259.55 \mathrm{x}+$ $\left.222.59 ; \mathrm{R}^{2}=0.998\right)$. The results were expressed in $\mu \mathrm{g}$ per $\mathrm{g}$ of dry weight $(\mathrm{dw})$, as mean \pm standard deviation of three independent analyses.

\subsection{Determination of antioxidant activity \\ 2.6.1. DPPH scavenging method}

The DPPH scavenging activity of different solvent extracts of E. kebericho was measured in term of hydrogen donating or radical-scavenging ability using the stable DPPH radical (Katerere and Eloff. (2005) with slight modification. Different concentrations $(50$ to $1000 \mu \mathrm{g} / \mathrm{mL})$ of the extracts were taken in different test tubes. Freshly prepared DPPH solution $(2 \mathrm{~mL}, 0.006 \%, \mathrm{w} / \mathrm{v})$ prepared in methanol was added in each of the test tubes containing $1 \mathrm{~mL}$ of the extract. The reaction mixture and the reference standard (BHT) were vortexed and left to stand at room temperature in the dark for $30 \mathrm{~min}$. The absorbance of the resulting solution was then taken at 520nm. Methanol was used as blank. The ability to scavenge the DPPH radical was calculated using the following equation:

$$
D P P H \text { scavenged }(\%)=\frac{(A c-A s)}{A c} \times 100
$$

Where $A \mathrm{c}$ is the absorbance of the control and $A \mathrm{~s}$ is the absorbance in presence of the sample of the extracts. The antioxidant activity of the extract was expressed as $\mathrm{IC}_{50}$. The $\mathrm{IC}_{50}$ value was defined as the concentration $(\mathrm{in} \mu \mathrm{g} / \mathrm{mL})$ of extracts that scavenges the DPPH radical by $50 \%$.

\subsubsection{Ferric ion reducing power}

The presence of antioxidants in the extract causes the reduction of the yellow ferric/ferricyanide complex to the ferrous form which can be monitored by measuring the formation of Perl's Prussian blue at $700 \mathrm{~nm}$ (Amarowicza et al., 2004). This assay was carried out as described previously by Oyaizu M. (1986) with minor modification. Plant extract $(1 \mathrm{~mL}$ ) solution (final concentration $50-1000 \mu \mathrm{g} / \mathrm{mL}$ ) was mixed with $5 \mathrm{~mL}$ sodium phosphate buffer $(0.2 \mathrm{M}, \mathrm{pH} 6.6)$ and $5 \mathrm{~mL}$ of $1 \%$ potassium ferricyanide. Then the mixture was incubated at $50^{\circ} \mathrm{C}$ for $20 \mathrm{~min}$. Trichloroacetic acid $(5 \mathrm{~mL}, 10 \%)$ was added to the mixture, which was then centrifuged at $3000 \mathrm{rpm}$ (Centurion, 1000 series, UK) for $5 \mathrm{~min}$. Finally, $5 \mathrm{~mL}$ of the supernatant solution was mixed with $5 \mathrm{~mL}$ of distilled water and $1 \mathrm{~mL} \mathrm{FeCl}{ }_{3}(0.1 \%)$ and absorbance was measured at $700 \mathrm{~nm}$. $\mathrm{IC}_{50}$ values $(\mu \mathrm{g} / \mathrm{mL})$ were calculated by plotting absorbance against the corresponding sample concentration, representing the effective concentration at which the absorbance was 0.5 for reducing power (Adhiraj et al., 2013). BHT was used as a reference compound.

\subsubsection{Statistical analysis}

The data were subjected to analysis of variance (ANOVA) and Duncan's multiple range tests were used for mean separation at $p<0.05$. Linear regression analysis was used to calculate $\mathrm{IC}_{50}$ value. Pearson correlations among antioxidant activities, total phenolic and flavonoid contents were considered at $p<0.05$.

\section{Results and Discussions}

\subsection{Determination of total phenolic and flavonoid contents}

The TPC in various solvent extracts from the root of $E$. kebericho varied widely, ranging from $7.58 \pm 0.45$ to 29.14 $\pm 0.38 \mathrm{mg} \mathrm{GAE} / \mathrm{g}$ (Table 1). The TPC followed the order: methanol $>$ water $>$ chloroform extracts. There was significant difference $(p<0.05)$ in TPC among the extracts. The aqueous $(92.24 \mathrm{mgGAE} / \mathrm{g})$ and methanol $(83.45$ mgGAE/g ) extracts of E. ritro and E. Tournefortii (Çiğdem et al., 2016) showed higher TPC than that of the present study. Whereas, the methanol $(23.52 \mathrm{mgGAE} / \mathrm{g})$ and chloroform $(1.87 \mathrm{mgGAE} / \mathrm{g})$ extracts of E. emiliae (Handam et al., 2017) showed lower TPC than the present study. The TFC varied from $0.66 \pm 0.02$ to $1.08 \pm 0.03$ $\mathrm{mg} \mathrm{QRE} / \mathrm{g}$ and decreased in the order of methanol $>$ water $>$ chloroform (Table 1). The TFC in these extracts were significantly different $(p<0.05)$. According to the study conducted by Handam et al. (2017), Echinops emiliae methanol (4.30 mgQRE/g ) and chloroform (2.14 mgGAE/g) extracts showed higher TFC than that of the present study.

Table 1. Total phenolic and flavonoid contents from E. kebericho root, extracted with different solvents.

\begin{tabular}{lcc}
\hline Extract & TPC $(\mathrm{mg} \mathrm{GAE} / \mathrm{g})^{*} \pm \mathrm{SD}$ & TFC $(\mathrm{mg} \mathrm{QRE} / \mathrm{g})^{* 2} \pm \mathrm{SD}$ \\
\hline Chloroform & $7.58 \pm 0.45^{\mathrm{a}}$ & $0.66 \pm 0.02^{\mathrm{a}}$ \\
Water & $17.47 \pm 0.88^{\mathrm{b}}$ & $0.91 \pm 0.081^{\mathrm{b}}$ \\
Methanol & $29.14 \pm 0.38^{\mathrm{c}}$ & $1.08 \pm 0.03^{\mathrm{c}}$ \\
\hline
\end{tabular}

Where $* 1$ and $* 2$ are total phenolic and total flavonoids expressed as gallic acid and quercetin equivalents, respectively. Values are expressed as mean $\pm \operatorname{SEM}(n=3)$ from triplicate experiments. Means with different letters in a column were significantly different at the level of $p<0.05$. 


\subsection{LC-MS analysis of phenolic compounds}

The quantifications of phenolics ( $\mu \mathrm{g} / \mathrm{g}$ dry matter) were accomplished by comparing retention times, mass and peak areas between the standards and the samples. Fourteen compounds were detected (Table 2), seven of which were phenolic acid derivatives, five flavonols, and two aliphatic organic acids. The peaks were characterized by the retention time and spectra against several standards. The concentration of succinic acid was extremely high when compared with the other two phenolic groups. In general hydroxycinnamic acid contained the highest where as caffeic acid the lowest. E. ritro L. had higher syringic acid but lower content of chlorogenic acid than that of the present study (Oksama et al., 2018). 4-Hydroxybenzoic acid was not detected in root extract of E. ritro, also the chlorogenic acid content of this plant $(0.001 \pm 0.0005 \mathrm{mg} / \mathrm{g})$ was smaller than that of the present study (138.16 $\pm 13.84 \mu \mathrm{g} / \mathrm{g})$. Similarly the hydroxycinnamic acid content of E. kebericho $(413.14 \pm 6.60 \mu \mathrm{g} / \mathrm{g})$ was higher than that of $E$. ritro $(0.003 \pm 0.0003 \mathrm{mg} / \mathrm{g})$. But the syringic acid content of the present study $(10.41 \pm 0.83 \mu \mathrm{g} / \mathrm{g})$ was lower than that of E. ritro L $(1.616 \pm 0.242 \mathrm{mg} / \mathrm{g})$.

Table 2. Spectral information and concentration of phenolic acids, flavonols, and aliphatic organic acids in methanol root extract of E. kebericho.

\begin{tabular}{lllll}
\hline Compound & MW & Parent ion $\left[^{\mathbf{M}-H]^{-}} \mathbf{~ m / z}\right.$ & tR $(\mathbf{m i n})$ & $\mu \mathbf{\mu} / \mathbf{g}$ of $\mathbf{~ d w}$ \\
\hline Phenolic acids & & & & \\
Chl & 354.31 & 353 & 3.33 & $138.16 \pm 13.84$ \\
4-hydrob & 138.12 & 137 & 4.03 & $222.94 \pm 34.51$ \\
Syr & 198.17 & 197 & 3.87 & $10.41 \pm 0.83$ \\
Fer & 194.15 & 193 & 5.59 & $3.83 \pm 0.48$ \\
Isofer & 194.18 & 193 & 6.07 & $7.73 \pm 2.36$ \\
Caf & 180 & 179 & 3.78 & $2.21 \pm 0.76$ \\
Cinam & 164.18 & 163 & 7.27 & $413.14 \pm 6.60$ \\
\hline Flavonols & & & & \\
Qu & 302.24 & 301 & 7.13 & $0.81 \pm 0.14$ \\
Q3-Glu & 464.38 & 462.78 & 5.90 & $5.58 \pm 0.28$ \\
Q3-Gal & 464.38 & 462.75 & 5.71 & $7.07 \pm 0.34$ \\
Q3-Rha & 448.38 & 446.75 & 6.61 & $0.80 \pm 0.05$ \\
Q3-Rut & 610.52 & 608.75 & 5.48 & $5.16 \pm 0.27$ \\
QRArGlu & 596 & 594.75 & 4.86 & - \\
\hline Aliphatic organic acids & & & & \\
Fum 116.07 & & 115 & 1.17 & $83.64 \pm 8.96$ \\
Suc 118.09 & 117 & 1.21 & $702.95 \pm 42.54$ \\
\hline
\end{tabular}

Within the class of flavonols, a total of six flavonols were identified and quantified in the extract (Table 2). Q3-Gal present in higher amount whereas qurecitin and Q3-Rha the lowest (below one microgram per gram of dreid root). The HPLC analysis showed that no quercetin-3-O-arabinoglucoside was present in the extract. Fumaric and succinic acids were the two aliphatic organic acids detected in the sample. Succinic acid was present in higher amount.

\subsection{Antioxidant activity based on DPPH scavenging}

DPPH radical is scavenged by antioxidants through the donation of hydrogen forming to the reduced DPPH. The color changes from purple DPPH radical to reduced yellow diamagnetic 2,2-diphenyl-1-picrylhydrazine molecule, which can be quantified by its absorbance reduction at wavelength $520 \mathrm{~nm}$ (von Gadow et al., 1997). The DPPH radical scavenging effects of root extracts are shown in Figure 1. As the concentration of sample increased, the percent inhibition of DPPH radical also increased (Huang et al., 2005). At the concentration of $1 \mathrm{mg} / \mathrm{mL}$ used, the DPPH radical scavenging effects were decreased in the order of BHT $(97.7 \pm 0.3 \%)>$ methanol extract $(95.31 \pm$ $1.2 \%)>$ water extract $(77.19 \pm 0.85 \%)>$ chloroform extract $(48.21 \pm 0.27 \%)$. 


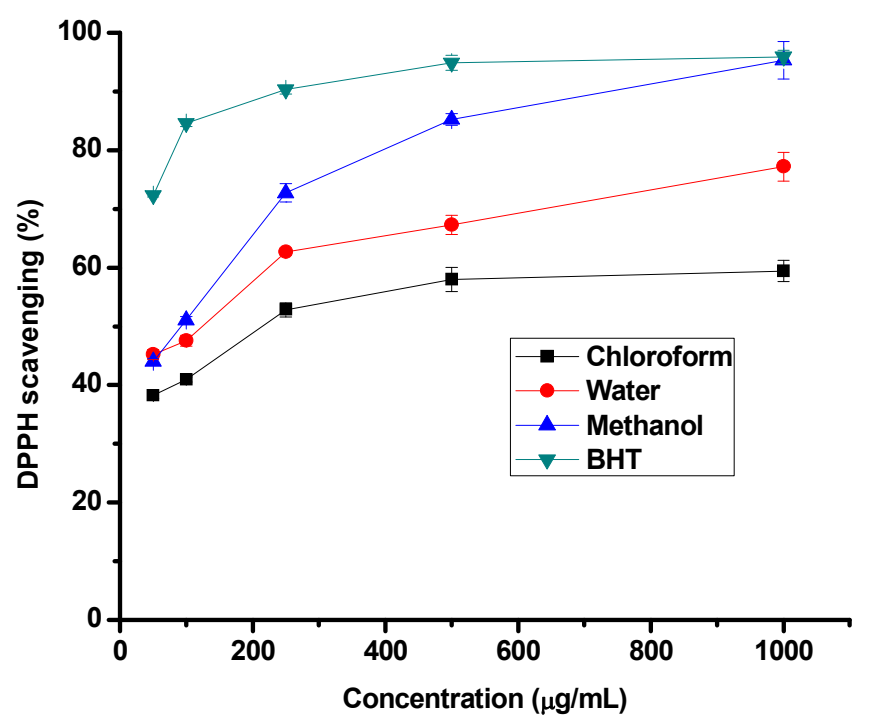

Figure 1. DPPH radical scavenging activity (\%) of chloroform, water, and methanol extracts from dried root extract of E. kebericho and control (BHT). Values are average of triplicate measurements (mean \pm SD).

The $\mathrm{IC}_{50}$ values of all the extracts were calculated from plotted graph of percentage scavenging activity against concentration of the extracts (Table 3 ). The lower the $\mathrm{IC}_{50}$ value, the higher is the scavenging potential. $\mathrm{The} \mathrm{IC}_{50}$ values ranged from $99.96 \pm 7.53 \mu \mathrm{g} / \mathrm{mL}$ for methanol extract to $176.76 \pm 7.91 \mu \mathrm{g} / \mathrm{mL}$ for chloroform extract. The values of all extracts were significantly different $(p<0.05)$ and strongest scavenging activity (lower $\mathrm{IC}_{50}$ values) was recorded for methanol extract. But the DPPH scavenging activity of all extracts was found to be significantly weaker $(p<0.05)$ than that of BHT. The DPPH scavenging activity of the methanol $\left(\mathrm{IC}_{50}=86.36 \pm\right.$ $0.002 \mu \mathrm{g} / \mathrm{mL}$ ) and chloroform $\left(\mathrm{IC}_{50}=68.18 \pm 0.005 \mu \mathrm{g} / \mathrm{mL}\right.$ ) root extracts of E. antalyensis (Handan and Vural, 2018) was stronger than that of the present study.

Table 3. $\mathrm{IC}_{50}$ values $(\mu \mathrm{g} / \mathrm{mL})$ of DPPH scavenging and ferric ion reducing power in various solvent extracts from root of E. kebericho.

\begin{tabular}{lll}
\hline Extract & $\mathrm{IC}_{50}(\mathrm{DPPH})$ & $\mathrm{IC}_{50}($ ferric reducing) \\
\hline Chloroform & $176.76 \pm 7.91^{\mathrm{d}}$ & $>1 \times 10^{3}$ \\
Water & $125.67 \pm 6.38^{\mathrm{c}}$ & $810.75 \pm 33.45^{\mathrm{c}}$ \\
Methanol & $99.96 \pm 7.53^{\mathrm{b}}$ & $246.88 \pm 15.60^{\mathrm{b}}$ \\
BHT & $35 . .54 \pm 1.20^{\mathrm{a}}$ & $51.10 \pm 1.68^{\mathrm{a}}$ \\
\hline
\end{tabular}

\subsection{Ferric reducing power}

Fe (III) reducing power of a compound is related to its ability to transfer electron and serves as a useful indicator of electron-donating activity, which is an important mechanism of phenolic antioxidant reaction (Rohman et al., 2010). The presence of antioxidants in the extracts causes the reduction of the $\mathrm{Fe}^{3+}$ /ferricyanide complex to the ferrous form. Therefore, the concentration of Fe2+ was monitored by measuring the formation of Perl's Prussian blue at $700 \mathrm{~nm}$ (Amarowicza et al., 2004). The results (Figure 2) showed the effects of extracting solvent on the reducing potential of the root of $E$. kebericho. The higher absorbance value indicates a higher reduction capacity. 


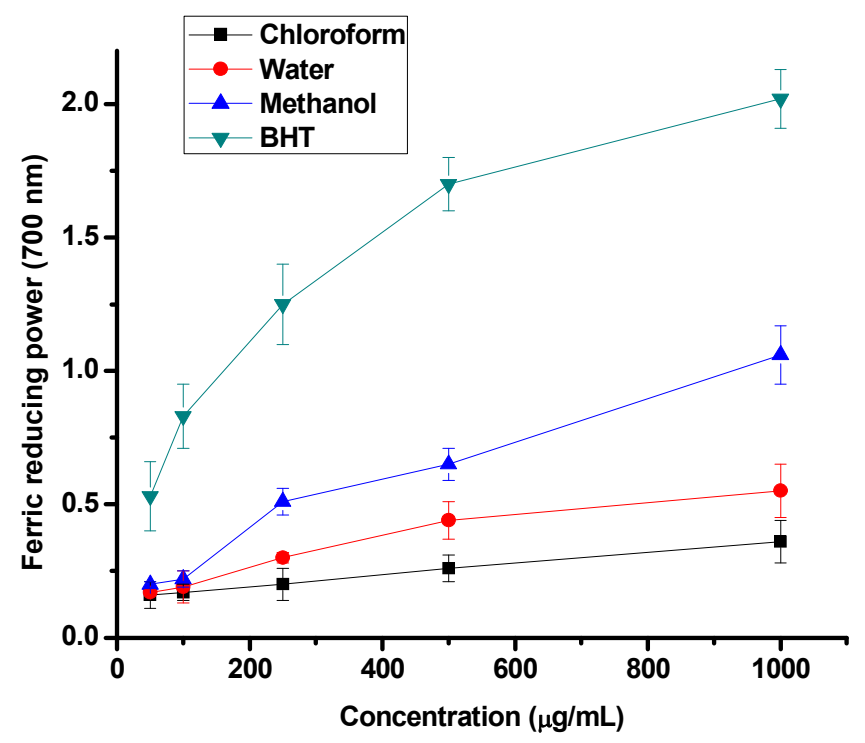

Figure 2. Ferric ion reducing power capacity various solvent extracts from dried root of E. keberiho at different concentrations. Values are average of triplicate measurements (mean $\pm \mathrm{SD}$ ).

At $1 \mathrm{mg} / \mathrm{mL}$, reducing power of the extracts was found to decrease in this order: BHT $(2.02 \pm 0.12 \mathrm{~nm})>$ methanol $(1.06 \pm 0.11 \mathrm{~nm})>$ water $(0.55 \pm 0.10 \mathrm{~nm})>$ chloroform $(0.36 \pm 0.08 \mathrm{~nm})$. Comparison of extracts showed variation of ferric reducing power. Methanol extract showed the strongest ferric reducing power with $\mathrm{IC}_{50}$ value of $246.88 \pm 15.60 \mu \mathrm{g} / \mathrm{mL}$, which appeared more than three times stronger than that of water extract and more than four times stronger than that of chloroform extract (Table 3 ).

\subsection{Correlation Analysis}

Phenolic and flavonoid molecules are important antioxidant components which are responsible for deactivating free radicals based on their ability to donate hydrogen atoms to free radicals or reduce the free radicals. Different studies indicate a linear correlation of total phenolic and flavonoid content with antioxidant capacity (Bakchiche et al., 2013; Engeda 2015). The correlations $\left(\mathrm{R}^{2}\right)$ between the antioxidant activity revealed by the two assays (DPPH and ferric reducing power) and TPC and TFC are represented in Table 4. The TPC was strongly correlated with DPPH scavenging and ferric reducing power. Similarly TFC was also strongly correlated with DPPH scavenging and well correlated with ferric reducing power. This indicates that phenolic compounds are phytochemicals which contribute to the antioxidant activity of this medicinal herb.

Table 4: Correlations between antioxidant activities of the various solvent extracts of E. kebricho and total phenolic and flavonoid contents $(p<0.05)$.

\begin{tabular}{lll}
\hline Antioxidant activities & TPC $(\mathrm{mgGAE} / \mathrm{g})$ & TFC $(\mathrm{mgQE} / \mathrm{g})$ \\
\hline DPPH scavenging $\left(\mathrm{IC}_{50}\right)$ & $0.93^{* *}$ & $0.98^{* *}$ \\
Ferric reducing power & $0.91^{*}$ & $0.71^{*}$ \\
\hline
\end{tabular}

* indicates significance at $\mathrm{p}<0.05, * *$ indicates significance at $\mathrm{p}<0.01$

\section{Conclusion}

In the present work, we characterized and quantified the phenolic compounds of root extract of endemic Ethiopian E. kebericho. Fourteen components were identified and the main components are hydroxycinnamic and succinic acids. For the first time, we demonstrate that the various extracts of the root of E. kebericho root exhibit antioxidant activity and methanol extract showed the highest total phenolic and total flavonoid contents and strongest antioxidant activity. The results obtained in this study show that the root extracts of E. kebericho may be a new potential source of natural antioxidants and antimicrobial agents. However, further studies need to be conducted to understand the mechanism of the activity of biomolecules and obtain more information on the safety and toxicity of the extracts. Therefore, it is necessary to investigate further and understand the relationship between antioxidant activity and chemical structure of each bioactive compound in the tested extracts.

\section{Conflicts of interest}

The authors declare that they have no conflicts of interest. 


\section{Acknowledgements}

The authors would like to acknowledge the Hawassa College of Education for the financial support, and also Dalhousie agricultural college, Canada for providing the laboratory facilities.

\section{References}

Abdissa, B., Ahmed, Z., Yonas, A., Lemu, G., Moti, Y., Asfaw, D., Geme, U., Bart, D. S. and Sultan, S. 2018. Zingiber Officinale Roscoe and Echinops Kebericho Mesfin Showed Antiplasmodial Activities against Plasmodium Berghei in a dose dependent manner in Ethiopia. Ethiopian Journal of Health Sciences, 28(5): $1-10$.

Abebe, D. and Ahadu, A. 1993. Medicinal plants and enigmatic health practices of NorthernEthiopia. Birhanna Selam Printing Press, Addis Ababa. pp 37-44.

Adhiraj, D., Manjula, R. and Krishnendu, A. 2013. Chemical Composition and Antioxidant Activity of a Wild Edible Mushroom Pleurotus flabellatus, International Journal of PharmTech Research, 5(4):655-1663.

Alemayehu, T., Serawit D., Abrham, F., Amelework, E. and Andrew, B. 2015. In vivo antiplasmodial and toxicological effect of crude ethanol extract of Echinops kebericho traditionally used in treatment of malaria in Ethiopia, Malaria Journal, 14:196.

Amarowicza, R., Pegg, R., Rahimi-Moghaddame, P., Barld, B. and Weilc, J. 2004. Free-radical scavenging capacity and antioxidant activity of selected plant species from Canadian prairies, Food Chemistry, 84:551562.

Ariaya, H. and Kidane, A. (1991). Screening for anthelmintic activity in two Echinops spp. Ethiopian Pharmceutical Journal, 9: 67-71.

Ariaya, H., Iversen, T. H., Rohloff, J. and Erko, B. 2005. Screening of Echinops ellenbeckii and Echinops longisetus for biological activities and chemical constituents. Phytomedicine, 12:675-79.

Ariaya, H., Jens, R., Tor-Henning, I., Helge, K. 2007. Volatile constituents of the roots of Echinops kebericho Mesfin, Flavour and Fragrance Journal, 22(1):35-38.

Ashebir, M. and Ashenafi, M. 1999. Evaluation of the antibacterial activity of crude preparations of Zingiber officinale (zinjibl), Echinops sp. (Kebericho), Coriandrum sativum (dimbilal) and Cymbopogan citratus (tej sar) on some food-borne pathogens, Ethiopian Journal of Health Science, 9:33-40.

Ayoola, G., Ipav, S., Solidiya, M., Adepoju-Bello, A., Coker, H. \& Odugbemi, T. 2008. Phytochemical screening and free radical scavenging activities of the fruits and leaves of Allanblackia floribunda oliv. (Guttiferae), International Journal of Health Research, 1: 81-93.

Bakchiche, B., Gherib, A., Smail, A., Custodia, G. Grac, M. 2013. Antioxidant activities of eight Algerian plant extracts and two essential oils. Industrial Crops and Products, 46:85-96.

Belay, G., Tariku, Y., Kebede, T., Hymete, A., Mekonnen, Y. 2011. Ethnopharmacological investigations of essential oils isolated from five ethiopian medicinal plants against eleven pathogenic bacterial strains. Phytopharmacology, 1:133-143.

Çiğdem, A., Gülten, T., Özcan, M. T. Ramazan, M. 2016. Phenolic Contents and Antioxidant Properties of Echinops ritro L. and E. tournefortii Jaup. Et. Spach Extract, International Journal of Secondary metabolite, $3(2): 74-81$.

Debela, A., Nigatu, K., Mirutse, G., Getachew, T. and Solomon, M. A. 2019. In vitro and In vivo antitrypanosomal activities of Echinops kebericho root extract, Biochemical research Methods.

Engeda, D. (2015). In Vitro Antioxidant and $\alpha$-Amylase inhibition activities of spiced red chili paste (Datta) from South Ethiopia, Ethiopian Pharmaceutical journal, 31:93-106.

Fisseha, S. and Workineh, S. 2013. In vivo antidiarrheal and ex-vivo spasmolytic activities of the aqueous extract of the roots of Echinops kebericho Mesfin (Asteraceae) in rodents and isolated guinea-pig ileum, International Journal of Pharmacy and Pharmacology, 2 (7):110-116.

Gadisa, D. 2019. Review on Ethnomedicinal and Pharmacological Uses of Echinops kebericho Mesfin in Ethiopia. Journal of Diseases and Medicinal Plants, 5(5):78-86.

Gemechu, A., Abdella, G. and Engida, D. 2016. A ntimicrobial Activity of Echinops kebericho Against human Pathogenic Bacteria and fungi, African Journal Traditional Complement and Alternative Medicine, 13(6):199-203

Handan Ş., Cem, V. Servet, Ö. 2017. Antimicrobial and Antioxidant activity of Echinops emiliae (Asteraceae) Int. J. Sec. Metabolite, 4(3) 400-405

Handan, Ş. and Vural C. 2018. Bioactivity researching on New Species of Echinops L. (Asteraceae):Antimicrobial and antioxidant Activity of Echinops antalyensis, Anadolu University Journal of Science and Technology CLife Sciences and Biotechnology, 7(1): 68-73.

Haung, D., Ou, B. \& Prior, RL. 2005. The chemistry behind antioxidant capacity assays, Journal of Agricultural and Food Chemistry, 53:1841-1856

Helen, B., and Ariaya H. 2019. The Genus Echinops: Phytochemistry and Biological Activities: A Review, 
Frontiers in Pharmacology, 10: 1-29.

Jemal, H., Kaba, U., Fayissa, R., Awol, J., Sultan, A. and Nezif, H. 2011. Antihelmentic effects of the essential oil extracts of selected medicinal plants against Haemonchus contortus, International journal of Agricultural research, 6:290-298.

Katerere, D. and Eloff, J. 2005. Antibacterial and antioxidant activity of Sutherlandia frutescens (Fabaceae), a reputed Anti-HIV/AIDS, Phytomedicine Phytotherapy Research, 19:779-781

Muluken, E. and Tileye F.. 2019. In vitro shoot regeneration from leaf explants of Echinops kebericho: an endangered endemic medicinal plant, Plant Biosystems, 153(2): 1-7.

Oksana, S., Irene, H., Marek, Z., Cornelia, R. Marian, B. 2018. Comparative analysis of bioactive phenolic compounds composition from 26 medicinal plants, Saudi Journal of Biological Sciences, 25: 631-641.

Rohman, A., Riyanto, S., Yuniarti, N., Saputra, W. R., Utami, R. \& Mulatsih, W. 2010. Antioxidant activity, total phenolic, and total flavaonoid of extracts and fractions of red fruit (Pandanus conoideus Lam), International Food Research Journal, 17:97-106.

Rupasinghe, H. P. V., Erkan, N., \& Yasmin, A. 2010. Antioxidant protection of eicosapentaenoic acid and fish oil oxidation by polyphenolic-enriched apple skin extract, Journal of Agricultural and Food Chemistry, 58: 1233-239.

Shan, B., Cai, Y., Sun, M. and Corke, H. 2005. Antioxidant capacity of 26 spice extracts and characterization of their phenolic constituents, Journal of Agricultural and Food Chemistry, 53: 7749-7759.

Tadesse, M. and Abegaz, B. 1990. A review of the Genus Echinops in Ethiopia with notes on phytogeography and Chemistry . Proceedings of the $12^{\text {th }}$ plenary meeting of AETFAT. 605-629.

Tariku, Y., Hymete, A., Hailu, A., Rohloff, J. 2011. In vitro evaluation of antileishmanial activity and toxicity of essential oils of Artemisia absinthium and Echinops kebericho, Chemistry and Biodiversity, 8: 614-623.

Teklehaymanot, T., Giday, M., Medhin, G. \& Mekonnen, Y. 2007. Knowledge and use of me-dicinal plants by people around Debre Libanos monastery in Ethiopia, Journal of Ethnopharmacology, 111(2): 271-283.

von Gadow, A., Joubert, E. \& Hansmann, C.1997. Comparison of the antioxidant aactivity of aspalathin with that of other plant phenols of Rooibos tea (Aspalathus linearis), $\alpha$-Tocopherol, BHT, and BHA, Journal of Agricultural and Food Chemistry, 45: 632-638.

Yonas, A., Zeleke, M., Ahmed, Z., Moti, Y., Abdissa, B. Sultan, S. 2018. Anti-schistosomal activities of Echinops kebericho Mesfin root and Hagenia abyssinica (Bruce) J.F Gmel flower part crude extracts in Swiss albino mice, Asian Pacific journal of tropical Medicine, 11 (10): 570-575. 